\title{
The Role of Important Values and Predominant Identity in the Dress Practices of Female Muslim Students Attending a South African University
}

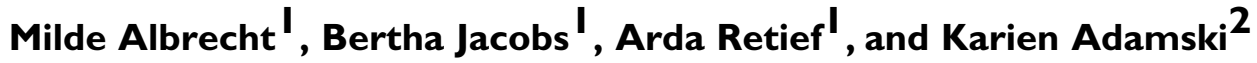 \\ 'Department of Consumer Science, University of Pretoria, Pretoria, South Africa \\ ${ }^{2}$ Department of Statistics, University of Pretoria, Pretoria, South Africa \\ Corresponding Author: \\ Milde Albrecht, Department of Consumer Science, University of Pretoria, Postnet Suite 21 I, Private Bag X3, Bloubergrant, \\ Cape Town 7443, South Africa. \\ Email: mildeshao@gmail.com
}

\begin{abstract}
This study explores the role of important values and predominant identity in the dress practices of female Muslim students attending a university in South Africa. Data were collected through a selfadministered questionnaire using a purposive convenience sample of 200 female Muslim students. A cluster analysis was used to divide participants into groups based on their dress practices. The sample could be divided into two groups: those who follow less modest and those who follow more modest dress practices. An independent $t$-test was calculated to determine if there was a significant difference between the important values and predominant identity of the less modest and more modest groups. The results revealed differences in the significance of certain values and predominant identity. The more modest group placed more importance on religious values, while the less modest group attributed more importance to social values than the more modest group. For the more modest group their Muslim identity was more predominant than for the less modest group. Despite these differences, both groups tended to communicate a hybrid identity, as aspects of Islamic and Western thought and behavior were synthesized in each individual's dress practice. The study offers benefits to scholars interested in the social-cultural aspects of clothing by showing how people manipulate their appearances and cultural forms to create a specific reality and to adapt to multicultural environments (e.g. campuses).
\end{abstract}

\section{Keywords}

values, identity, dress practices, Muslim students 
Islam is the fastest growing religion in the world (Sader, 2008). Muslims make up $24 \%$ of the world population (Kettani, 2010), but this number is expected to increase by about $35 \%$ in the next 20 years, from 1.6 billion in 2010 to 2.2 billion by 2030. In 2001, Muslims constituted $1.46 \%$ of the total South African population. The representation of Muslims with regard to the total South African population is expected to continue its slow increase (Kettani, 2010). Although Muslims are a minority group in South Africa (Vahed, 2000), the presence of their culture is highly visible. Large mosques are found in every major city, and Muslim women in traditional dress can be seen everywhere (Vahed, 2000).

South Africa is known as the "rainbow nation" as a result of the diversity of cultures within its borders (Khan, 2013). While it is difficult to label South Africans according to one national identity, two main cultural orientations exist, namely, an African identity and a Western one (Bornman, 2005; Vahed, 2000). These two cultural orientations are evident in South African dress practices. South African Muslim women follow a variety of dress practices, ranging from traditional Islamic dress to more revealing Western fashions (Kopp, 2002; Muthal, 2010). For these women, cultural aspects such as dress practices cannot be separated from religious ties to the Islamic faith (Tawfiq \& Ogle, 2013). Dress serves as an instrument to describe its wearer in terms of cultural origin and communicates internal aspects such as cultural values and cultural identity underpinning behavior (Forney \& Rabolt, 1997; Rovine, 2009). Cultural differences are accentuated through different dress practices, and in this manner, unique cultural identities are created (Rovine, 2009).

Various international studies have focused on the values and identities that underpin Muslim women's dress practices. Dwyer (2000) analyzed how young British Muslim women negotiated their identities by means of their dress. Sirin et al. (2008) indicated that participants were able to incorporate both their Muslim and American identities, either as a coherent whole or in separate domains of life. Sader (2008) focused on the identity negotiations of South African Muslim women who were married and employed. There are, however, limited studies focusing on the values, identities, and dress practices of Muslim women living in a South African context and, more specifically, those of female Muslim students. An investigation into the dress practices of female Muslim students in South Africa can provide a better understanding of this cultural group's beliefs and unique dress practices (Boulanouar, 2006).

The purpose of this study was to explore and determine the most important values (i.e., social, religious, economic, political, aesthetic, theoretical, and exploratory) and predominant identity (i.e., ethnic, national, and hybrid) of female Muslim students attending a university in South Africa. This research study fills an important contextual gap in existing knowledge on the behavior of Muslim women in terms of their dress practices as related to their values and identity.

\section{Theoretical Framework}

Culture can be both material and nonmaterial in nature. Dress practices forming part of material culture are a reflection of underlying concepts such as values and identity (nonmaterial culture; Chattalas \& Harper, 2007; Kaiser, 1997; Momcilovic, 1998). Individuals are committed to the identities that best enable them to express their most important values (Arthur, 2000; Hitlin, 2003). Values and identity are both expressive in nature, and individuals are motivated to communicate them to others through their appearances (Kaiser, 1997). The cultural perspective recognizes the relationship between the material and nonmaterial aspects of culture and provided a framework for this study to determine how abstract concepts, such as values and identity, manifest in dress (Kaiser, 1997).

Culture refers to the lifestyle of a group of people and may consist of various ethnic groups. These ethnic groups may share a common ancestry, place of origin, language, or religion (Boonzaier \& Sharp, 1988; Phinney, Horenczyk, Liebkind, \& Vedder, 2001; Rajagopalan \& Heitmeyer, 2005). Religion may 
be central within a certain cultural system and therefore its various ethnic groups. A religion's outward manifestations represent the rules, customs, conventions, and rituals of the cultural group. Dress therefore plays an important role in the religious expression of group members (Arthur, 2000).

Religiosity is the main variable contributing toward strong Muslim identification (Muthal, 2010; Sirin et al., 2008). Islam prescribes the dress practices, values, and overall identity of its followers (Dastoor, Baumanis, \& Soomro, 2003). In South Africa, the Muslim culture consists of various ethnic groups including Indian, Malay, and African Muslims (Hassan, 2011). These group members have a shared understanding of important values and communicate a collective identity through their outward appearances (Markus \& Kitayama, 1991; Storm, 1987). Values, identity, and dress are all subject to change due to cultural contact (Kaiser, 1997). The South African university experience may have resulted in female Muslim students' modification of their traditional dress practices into more westernized dress, or a combination of Muslim and Western dress.

\section{Literature Review}

\section{Values}

Values are deeply held, culturally learned beliefs that certain patterns of behavior or end states are preferable to others (Rokeach, 1973). Ethnic background, age, gender, level of education, religion, and social class influence the amount of importance that individuals place on their values (Dastoor et al., 2003; Pentecost, 1973). Individuals tend to behave according to their most important values and express these values to others (Bardi \& Schwartz, 2010). Values are therefore important motivational forces in decision making and may be reflected in people's dress practices (Hitlin, 2003; Kaiser, 1997).

Allport, Vernon, and Lindzey (1960) proposed six basic values. These include aesthetic, theoretical, economic, political, social, and religious values (Momcilovic, 1998; Storm, 1987). Creekmore (1963) related clothing behavior to these basic values and suggested a seventh value type, namely, that of exploratory values (Jain, Singh, \& Rankawat, 2011; Momcilovic, 1998).

People with dominant aesthetic values place great importance on fashion, enjoyment, and enhancing personal appearance (Storm, 1987). They value the design and expressive quality of an object (Pentecost, 1973). Political values refer to the desire to obtain power and success. These values are related to fashionable dress and status symbolism (Kaiser, 1997; Storm, 1987). Exploratory values emphasize novelty and variety (Kaiser, 1997). Such individuals want to experiment with different clothing styles (Kaiser, 1997). Theoretical values are related to the practicality and comfort of dress (Kaiser, 1997). Social values are linked to conformance in dress, as individuals feel the need for acceptance by others and, therefore, dress according to social expectations (Kaiser, 1997; Momcilovic, 1998). Religious values are related to modest dress and a low fashion interest (Kaiser, 1997; Storm, 1987). Economic values involve satisfying basic needs and avoiding wastefulness in terms of time, money, and energy (Kaiser, 1997).

\section{Identity}

Identity refers to a self-definition and can be defined as "the organized set of characteristics an individual perceives as representing or defining the self in a given social situation" (Kaiser, 1997, p. 186). Dress is a means of establishing, reinforcing, and communicating one's identity (Rovine, 2009). Clothing announces who we are as well as who we want to be (Arthur, 2000; Chattalas \& Harper, 2007). South African Muslim women attach various meanings to their identity and communicate these identities through their dress (Muthal, 2010). Three different types of identity they may communicate include ethnic, national, and hybrid identities.

Ethnic identity derives from one's cultural heritage and refers to a sense of self as a member of an ethnic group (Chattalas \& Harper, 2007; Phinney \& Ong, 2007). The veil gives Muslim women a strong 
ethnic identity (Hassem, 2008). To cover the body and conceal it from view is a moral commitment under Islam (Dunkel, Davidson, \& Qurashi, 2010; Kilicbay \& Binark, 2002). Islam prohibits women from wearing clothing that is transparent or tight-fitting (Boulanouar, 2006). The term hijab describes the standard requirements of Islamic clothing for women and literally means "curtain" or "barrier" (Dunkel et al., 2010). Hijab has differing meanings in terms of the type of covering it includes. Some Muslims feel hijab refers to a head covering accompanied by loose-fitting clothing (Dwyer, 2000; Hassem, 2008). Others believe it only refers to a head covering (Boulanouar, 2006). Either way, by wearing hijab, a Muslim woman communicates her commitment to Islam (Shirazi, 2000).

National identity refers to a common public culture that unites the members of one community or society and distinguishes it from others (Henderson \& McEwen, 2005). South Africa is a multicultural nation with a collective heritage (Sader, 2008; Van Der Merwe, 1996). As discussed above, two main cultural orientations exist in this nation, namely, an African identity and a Western one (Bornman, 2005). These cultural orientations are evident in South African dress practices. Due to the long period of European control over South Africa, Western clothing styles became part of the African existence (Vincent, 2007). Western fashions are based on change, by focusing attention on different parts of the body (Frings, 2005). Dunkel, Davidson, and Qurashi (2010) referred to Western dress as being standard American clothing, while Ferguson (2002) considered Western dress forms as originating from Europe. Women's Western-styled garments are typically more tailored and fitted, including suits, T-shirts, and blue jeans (Rovine, 2009). South Africans embrace their national identity by combining local trends with Western garments. One example is T-shirts printed with political figures from South Africa's past. The African aesthetic thus shapes mainstream fashions in order to create clothing trends that are unique to this nation (Musangi, 2009; Vincent, 2007).

A hybrid identity is created when ethnic and national identities are combined (Dwyer, 2000; Phinney \& Ong, 2007). Hybridity refers to cultural overlapping of oppositional ways of thinking and behaving. Both cultures are permanently present in the individual, no matter to what extent (Schumann, 2011). A hybrid identity can be communicated through dress (Naylor, 1996). Kim and Farrell-Beck (2005) found that South Korean female students adopted Western forms of casual dress, such as jeans, and combined them with more formal garments. Modesty in dress was a deeply rooted cultural value to Koreans. These students therefore wanted to be properly dressed according to their culture's expectations, while at the same time appear fashionable (Kim \& Farrell-Beck, 2005). South African Muslim women have also been found to creatively construct their dress to communicate a hybrid identity (Sader, 2008; Vahed, 2000).

\section{Campus Context}

The campus environment is known to be a multicultural context, where students from various backgrounds interact with one another on a daily basis (Bennett, Volet, \& Fozdar, 2013). Students find different ways of adapting to this new context. In order to make the transition from high school to university, values and identities may be transformed (Peek, 2005). Peek (2005) found that American Muslim students became more religious when they went to college. Due to the campus context being vast and multicultural, they found many other Muslim students to form friendships with. These new peer groups served as a support system for their religious identities. Most of the women forming part of the study wore hijab on campus in order to visibly communicate this identity. One participant stated:

In high school I was not very religious. It was in college that I developed a renewed interest in Islam. Being with other Muslims was a factor. People are open as Muslims. In high school they weren't. In college you have more freedom. You're exposed to different ideas and cultures. You're encouraged to experiment. (Peek, 2005, p. 228) 
Female Muslim students attending a university in South Africa follow varied dress practices. External cultural artifacts, such as dress, communicate internal aspects about an individual (Kaiser, 1997). We explored these internal aspects including values and identity, in order to understand the differences in dress of a cultural group who traditionally placed great importance on a modest dress code (Dunkel et al., 2010). Other researchers have found Muslim individuals forming part of minority groups in certain countries to creatively construct their appearances in order to communicate both their original and the dominating values and identities of the society they are living in (Dwyer, 2000; Sader, 2008; Sirin et al., 2008; Vahed, 2000). A South African university context provides the ideal environment to investigate how the multitude of cultural orientations and religious views influence female Muslim students' values, identities, and dress practices.

\section{Research Objectives}

The overall objective of the study was to understand how values and identity affect female Muslim students' dress practices on campus. Specific objectives of the study were:

1. To explore and describe the most important values (i.e., social, religious, economic, political, aesthetic, theoretical, and exploratory) of female Muslim students as reflected in their dress practices.

2. To explore and describe the predominant identity (i.e., ethnic, national, and hybrid) female Muslim students want to communicate with their everyday dress practices.

\section{Method}

To explore and describe the role of values and identity in the dress practices of female Muslim students in a campus context, the researchers followed a survey research design. Reliable scales for values were adapted from Allport et al. (1960) and Bardi and Schwartz (2010). Scales measuring participants' predominant identity were adapted from Phinney and Ong (2007) and Benet-Martinez and Haritatos (2005) in order to relate to participants' dress practices.

\section{Sample and Sampling Procedure}

The target population consisted of the 354 female Muslim students enrolled at a university in South Africa in 2011 (Y. Du Plessis, personal communication, September 4, 2011). Data were collected from a purposive convenience sample of 200 female Muslim students between the ages of 17 and 25 years. Purposive sampling was used to recruit female Muslim students to voluntarily complete the self-administered questionnaire. By answering several screening questions (e.g., length of stay in South Africa, number of years being a Muslim, age, and number of days per week on campus), it was ensured that participants met the outlined criteria. Participants needed to be female and Muslim. They were required to have been enrolled at a specific South African university at the time of completing the questionnaire. Participants were only approached on the campus grounds. The questionnaires were completed during the period of October 2011 to March 2012. Care was taken not to distribute the questionnaire during religious holidays of the Islamic calendar, such as Eid and Ramadan. Questionnaires were also not distributed on Fridays, as this is a holy day for Muslims and might have influenced how participants filled in the questionnaires. The researcher took care to include participants following various dress practices ranging from a traditional Islamic appearance to those with a Western appearance. 


\section{Data Analysis}

SAS (version 9.3), BMDP (version 8.1), and Statistica (version 10) software were used to perform statistical analysis. The reliability of the value constructs (aesthetic, theoretical, economic, political, social, religious, and exploratory) and identity constructs (Muslim, South African, and hybrid) was assessed using Cronbach's $\alpha$.

A cluster analysis was conducted in order to divide the sample into clusters that share common characteristics in terms of their dress practices. Items that received high variation in ratings by participants in terms of being worn frequently on campus were used in the cluster analysis. The items included hijab and headscarf, tight-fitting jeans and T-shirt, headscarf with Western garments, and headscarf with loose-fitting top and tight pants. An independent $t$-test or analysis of variance (ANOVA) is calculated to determine whether clusters are "conceptually distinguishable" (Mooi $\&$ Sarstedt, 2011). The Kruskal-Wallis test, the nonparametric equivalent of the one-way ANOVA, was calculated to ascertain whether the differences in dress practices separated the clusters adequately (Field \& Miles, 2010). Dividing the sample into two groups based on their dress practices yielded satisfactory results. For this study, the two groups were named Group 1: less modest dress practices $(n=104)$ and Group 2: more modest dress practices $(n=96)$. Participants forming part of Group 1 stated that they follow less modest dress practices than Group 2, as they tended to not wear headscarves when on campus and preferred to wear typical Western garments. Participants forming part of Group 2 indicated that they follow a more modest dress code than Group 1 when on campus by regularly wearing headscarves or other traditional Islamic garments.

\section{Results}

\section{Sample Characteristics}

All the participants were female and of the Muslim religion. Almost half $(48.5 \%)$ of the participants were between the ages 17 and 19, 46\% were between the ages 20 and 22, and 5.5\% between 23 and 25 years. The majority of participants $(88 \%)$ indicated that they have been living in South Africa their whole life, while $8.5 \%$ of the participants have lived in South Africa for less than or equal to half their life. Almost all of the participants (97\%) have been Muslim for their whole lives. The other $3 \%$ indicated that they have been a Muslim for less than or equal to half their lives. Most participants $(62 \%)$ indicated that they are on campus for the whole week ( 5 days), while $36 \%$ of the participants indicated that they are on campus 3 to 4 days per week.

\section{Dress Practices}

Many of the participants were found to place great importance on their Muslim identity and values when managing their dress practices. Most of the participants (73.5\%) required their dress to communicate their affiliation to their Muslim background rather than to their South African identity. The majority of participants $(96.5 \%)$ indicated that their clothing should communicate their participation in Muslim customs, their dedication to their Muslim heritage (92.5\%), and their association with other Muslim students (91.5\%).

Many participants were found to emphasize both their Muslim and South African values and identities in their daily dress practices. The majority of participants $(82.5 \%)$ required their dress to communicate their participation in both Muslim and South African activities. Many of the participants (72\%) indicated that they combine South African fashion trends with their Islamic garments, and $53.5 \%$ specified that they alternate between Muslim and Western clothing styles.

Few participants indicated that they aimed to communicate South African rather than Muslim values and identities when dressing for the campus environment. Less than half of the participants 
Table I. Cronbach's $\alpha$ for All Value and Identity Constructs.

\begin{tabular}{|c|c|c|}
\hline Construct & Items & $\begin{array}{l}\text { Cronbach's } \alpha \\
\text { for Construct }\end{array}$ \\
\hline Aesthetic values & $\begin{array}{l}\text { Makes me feel attractive } \\
\text { Is beautiful } \\
\text { Is eye-catching } \\
\text { Enhances my beauty }\end{array}$ & .86 \\
\hline Theoretical values & $\begin{array}{l}\text { Is comfortable } \\
\text { Is practical for campus activities } \\
\text { Is easy to move around in while walking to class }\end{array}$ & .86 \\
\hline Economic values & $\begin{array}{l}\text { Is timeless and will not become outdated } \\
\text { Can be used for more than one occasion } \\
\text { Will last a long time } \\
\text { Is value for money }\end{array}$ & .84 \\
\hline Exploratory values & $\begin{array}{l}\text { Shows my creativity in how I dress } \\
\text { Shows my individuality } \\
\text { Shows I am free to dress how I want } \\
\text { Shows I experiment with different looks } \\
\text { Is in line with fashion trends }\end{array}$ & .81 \\
\hline Political values & $\begin{array}{l}\text { Is admired by others } \\
\text { Looks expensive } \\
\text { Comes from an impressive brand name } \\
\text { Influences others to wear the same clothing as me }\end{array}$ & .78 \\
\hline Social values & $\begin{array}{l}\text { Allows me to blend in with other students } \\
\text { Fits in with my friends' clothing } \\
\text { Is accepted by my friends }\end{array}$ & .77 \\
\hline Muslim ethnic identity & $\begin{array}{l}\text { I am dedicated to my Muslim heritage } \\
\text { I am a Muslim, rather than a South African } \\
\text { I associate myself with other Muslim students } \\
\text { I participate in Muslim activities } \\
\text { I take part in Muslim customs } \\
\text { I dress according to Muslim expectations }\end{array}$ & .68 \\
\hline Hybrid identity & $\begin{array}{l}\text { I am proud to be a South African Muslim } \\
\text { I am both a Muslim and a South African } \\
\text { I associate myself with students from the Muslim culture as well as } \\
\text { those from other cultures } \\
\text { I participate in both Muslim and South African activities } \\
\text { I combine South African fashion trends with my Islamic garments } \\
\text { I alternate between Muslim and Western clothing styles }\end{array}$ & .68 \\
\hline Religious values & $\begin{array}{l}\text { Is not revealing } \\
\text { Is not tight-fitting } \\
\text { Shows I respect my parents' wishes as to how I should dress } \\
\text { Shows I respect my religion } \\
\text { Does not offend others } \\
\text { Does not attract attention to myself }\end{array}$ & .64 \\
\hline $\begin{array}{l}\text { South African national } \\
\text { identity }\end{array}$ & $\begin{array}{l}\text { I am proud to be a South African } \\
\text { I am a South African, rather than a Muslim } \\
\text { I associate myself with students from other cultures, rather than from } \\
\text { the Muslim culture } \\
\text { I participate in South African activities } \\
\text { I follow South African fashion trends } \\
\text { I prefer to dress like other South Africans }\end{array}$ & .59 \\
\hline
\end{tabular}


Table 2. Independent $t$-Tests for All Value and Identity Constructs.

\begin{tabular}{lccc}
\hline Construct & Group I: Less Modest Mean (SD) & Group 2: More Modest Mean (SD) & $p$ Value \\
\hline Social values & $2.91(1.124)$ & $2.32(0.995)$ & $<.00 I^{*}$ \\
Religious values & $4.12(0.591)$ & $4.39(0.538)$ & $<.00 I^{*}$ \\
Economic values & $3.84(0.925)$ & $4.03(0.920)$ & .143 \\
Theoretical values & $4.59(0.706)$ & $4.69(0.538)$ & .260 \\
Political values & $2.51(0.999)$ & $2.38(0.976)$ & .320 \\
Aesthetic values & $3.52(1.031)$ & $3.38(1.060)$ & .366 \\
Exploratory values & $3.79(0.891)$ & $3.74(0.963)$ & .666 \\
Muslim ethnic identity & $4.15(0.548)$ & $4.48(0.449)$ & $<.00 I^{*}$ \\
South African national identity & $3.27(0.507)$ & $3.11(0.631)$ & .046 \\
Hybrid identity & $4.24(0.517)$ & $4.24(0.558)$ & .973 \\
\hline
\end{tabular}

*Significant with $p<.01$.

(49\%) stated that they follow South African fashion trends, and only $16 \%$ preferred to dress like other South Africans. Hardly any participants $(6 \%)$ required their dress to communicate that they are a South African rather than a Muslim. Only 39.5\% of the participants wanted their dress to communicate their association with students from other cultures rather than from the Muslim culture.

\section{Reliability}

The items that represented each construct in the questionnaire as well as Cronbach's $\alpha$ values for each construct are given in Table 1. Cronbach's $\alpha$ values indicated that reliability for most constructs was high (between 0.64 and 0.86 ) except for a South African identity $(\alpha=0.59)$, indicating a recommended standard and a good level of internal consistency for almost all constructs (Field \& Miles, 2010).

\section{Importance of Values for Two Groups}

The results of the independent $t$-tests are given in Table 2 . The results indicated that the mean score of social values for the less modest group $(n=104 ; M=2.91 ; S D=1.124)$ and more modest group $(n=96 ; M=2.32 ; S D=0.995)$ differed significantly $(p<.001)$. The less modest group had a higher mean score in terms of their social values than the more modest group. For the less modest group, social values were more important than for the more modest group.

For religious values, the mean score also differed significantly $(p<0.001)$ between the less modest group $(n=104 ; M=4.12 ; S D=0.591)$ and the more modest group $(n=96 ; M=4.39$; $S D=0.538$ ). The less modest group had a lower mean score in terms of their religious values than for the more modest group. For the less modest group, religious values were less important than for the more modest group. No significant difference in the importance the groups placed on economic, political, aesthetic, exploratory, and theoretical values were found.

\section{Ranking of Values}

All values for the two groups were ranked in the same order of importance according to their medians (1 Theoretical; 2 Religious; 3 Economic; 4 Exploratory; 5 Aesthetic; 6 Social; 7 Political). An overall difference in the medians of the seven constructs were indicated for the two groups separately ( $p<.001$ for both groups). Post hoc tests were performed to determine where the differences lie. The post hoc tests were performed on a $5 \%$ level of significance. For the less modest group, 
theoretical values are the most important and political values the least important. For the more modest group, theoretical and religious values are equally the most important with social and political values being equally the least important value types.

\section{Predominant Identity of Two Groups}

The results of the independent $t$-tests are given in Table 2 . The results revealed that the mean score of a Muslim identity differed significantly $(p<.001)$ between the less modest group $(n=104$; $M=4.15 ; S D=0.548)$ and the more modest group $(n=96 ; M=4.48 ; S D=0.449)$. The more modest group had a higher mean score in terms of their Muslim identity than the less modest group. For the more modest group, their Muslim identity was more predominant than for the less modest group. There was no significant difference between the two groups' preferences for a South African or hybrid identity.

\section{Ranking of Identities}

For both groups, all three identity types were ranked in the same order with the same differences in importance indicated for all variables (1 Muslim ethnic identity; 2 Hybrid identity; and 3 South African national identity). A Muslim and hybrid identity did not differ significantly from one another. They did, however, differ significantly from a South African identity in terms of the median values.

\section{Discussion}

The overall purpose of the study was to explore and describe the important values and predominant identities of female Muslim students as related to their dress practices. Cluster analysis revealed that the sample could effectively be divided into two groups based on participants' dress practices. The formation of these two groups is visible in the conceptual framework in Figure 1. All the participants were found to follow a bicultural strategy, as they identified with aspects of both their Muslim and South African backgrounds. They were, however, found to be bicultural to different degrees. Participants forming part of the first group $(n=104)$ were said to follow less modest dress practices, as they identified more with a Western way of dressing (e.g., jeans and T-shirt). Participants forming part of the second group $(n=96)$ followed more modest dress practices, as they indicated that they wear traditional Islamic garments on a regular basis (e.g., headscarf).

\section{Important Values}

For both groups, all values were ranked in the same order of importance. Statistical procedures indicated that the more modest group attributed more importance to religious values, while the less modest group placed more importance on social values. Each value will be discussed in descending order according to its importance.

Theoretical values. For both groups, theoretical values were ranked as the most important value type. The majority of participants (98\%) indicated that they are on campus 3 to 5 days per week. Students want their clothing to be practical for the campus environment. It is likely that female Muslim students may prefer to wear garments that are suitable to South Africa's climate, which can be very hot in the summer months, and may discard some of their traditional Islamic garments in order to feel more comfortable while moving around on campus. Wahl (2014) focused on South African Muslim converts and quoted a participant as saying, "Because of the country that we're living in, it's comfortable to wear jeans and a top, to dress relaxed" (Wahl, 2014, p. 100). Islamic and Western garments may be combined in order to create the most functional ensemble for the campus context. 


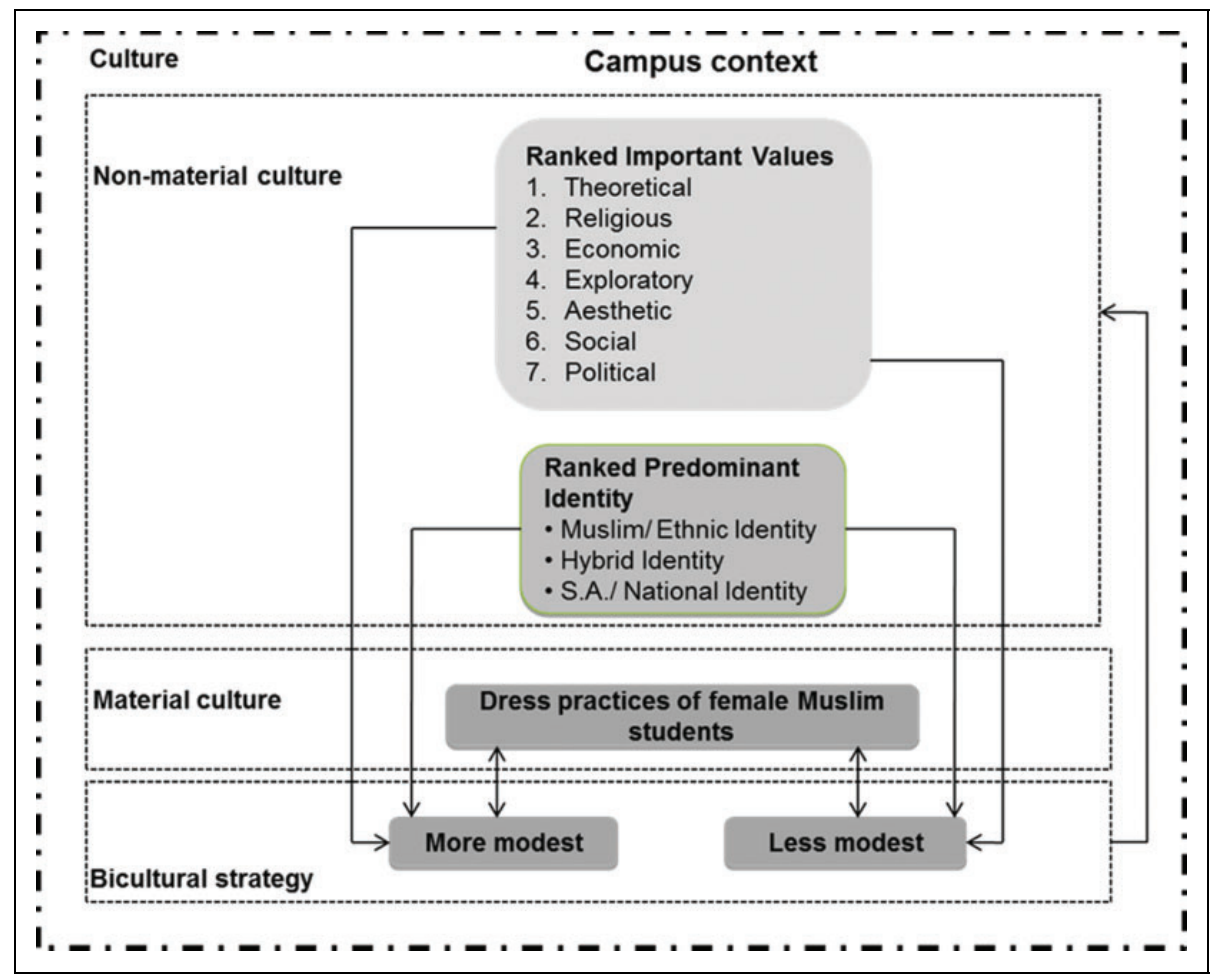

Figure I. Conceptual framework. This figure illustrates the bicultural strategies that can be followed in the campus context to express the nonmaterial aspects of culture through material culture, namely dress practices.

These findings are supported by the assumption of the cultural perspective, which is that "collective values are produced and reproduced through cultural forms" (Kaiser, 1997, p. 49). The campus context may have resulted in female Muslim students placing more importance on theoretical values and therefore having collectively changed their dress to suit the new environment.

Religious values. Both groups scored religious values as their second most important value. This may be the result of most of the participants (97\%) having been Muslim all their lives. The $t$-test revealed that the more modest group placed more importance on this value type than the less modest group. All participants identified themselves as being Muslim. The more modest group is, however, more in line with the requirements of the Islamic faith since they tend to wear traditional Islamic garments on a regular basis. One of the assumptions of the cultural perspective is that "cultural beliefs and values tend to be perpetuated when they are represented on a relatively unconscious level" (Kaiser, 1997, p. 49). Religious values are so ingrained within Muslim individuals that despite being surrounded by other cultures, they still place great importance on this value type. Female Muslim students enrolled at a university in South Africa hold onto their Muslim heritage and demonstrate their dedication to their Muslim background by wearing Islamic garments.

Economic values. The third most important value for both groups was economic values. All participants in the current study needed to be enrolled at a university in South Africa in order to have taken part in the study. University students are known to have a low spending power, as they are still studying and usually do not earn a stable income. For this reason, it is understandable that participants 
would want their clothing to be a good value for the money and to last a long time. Participants scored this value type highly as they wanted their clothing to be timeless and to be worn for more than one occasion. This finding is in line with Hsu's (2003) study where college students from both Taiwan and the United States scored economic values as the most important value type when making clothing decisions.

Exploratory values. The fourth most important value for both groups was exploratory values. The university experience is the most versatile time of life where students are on a journey of selfdiscovery. This is a period where individuals want to experiment and find their own style of dress (Jain et al., 2011). Participants may place importance on this value, as they enjoy experimenting with new looks within the campus environment that is away from their parents' and neighbors' watchful eyes. The cultural perspective states that "people have the potential to transform their own realities by manipulating the objects in their cultural world" (Kaiser, 1997, p. 51).

Female Muslim students merge Islamic and Western clothing styles in unique ways. The combination of Islamic and Western garments into one outfit has quite a shocking effect, as these dress forms come from contradictory worlds. Western fashions are fast changing and are associated with individuality (Balasescu, 2003; Frings, 2005). Islamic dress is associated with holding deep meanings, being unchanging, and projecting group identity (Fernea \& Fernea, 1995; Rovine, 2009). Participants have therefore broken these dress conventions and created new clothing styles.

Aesthetic values. Both groups rated aesthetic values as the fifth most important value type. This value received above-average ratings overall. According to Kaiser (1997), gender roles dictate that men need to be physically effective, whereas women need to be physically attractive. Women are rewarded for their appearance and therefore take great care to look beautiful (Kaiser, 1997). All participants in the study were female, which explains why they rated aesthetic values positively. Western ideals of beauty are increasingly influencing the rest of the world with cultural groups becoming more similar in appearance (Dunkel et al., 2010). The fact that many participants in the current study have adopted Western forms of dress to some degree affirms that the cultural contact they experience on a daily basis may have resulted in a shift in their beauty standards, thus resulting in their discarding of some Islamic forms of dress.

Female Muslim students attending a university in South Africa are surrounded by Western influences on campus. It is possible that the daily interaction with students from other cultural backgrounds may have influenced participants to adopt some Western dress forms and to express these aesthetic values through their dress.

Social values. Social values were rated as the sixth most important value by both groups and received below-average importance ratings. The results of the $t$-test disclosed that the less modest group placed slightly more importance on this value type than the more modest group. A possible reason why the less modest group found social values to be more important is that these individuals feel a greater need to fit into the campus context. They tend to wear more Western garments and appear similar in appearance to other students. Social values did, however, receive low ratings from both groups, with participants placing more importance on exploratory values. This is an indication that participants are more concerned with expressing their individuality than conforming to the dress practices of others when on campus. These individuals may not be concerned with comparing themselves to others and may rather prefer to emphasize their uniqueness.

Political values. Political values were the lowest ranked value by both groups. Participants can most likely not afford to buy impressive brand names or follow all the latest fashion trends. Participants 
rather want clothing that will not become outdated quickly and that is value for money. Political values (the equivalent of Schwartz's power and achievement values) have proven to be a low-scored value type throughout many studies, despite the sample's characteristics. Studies focusing on high school students, nurses, teachers, and professional women have all found this value type to be rated as less important than most other values, with Schwartz's power value consistently being rated as the least important value type (Glazer \& Beehr, 2002; Hofmann-Towfigh, 2007; Schwartz \& Bardi, 2001; Smith, De Klerk, \& Fletcher, 2011). It is evident that individuals either do not relate to this value type or do not like to admit that they place importance on status symbolism and personal image. This holds true for the current study where participants also did not identify with political values.

\section{Predominant Identity}

For both groups, all identities were ranked in the same order of importance. Statistical procedures indicated that a Muslim identity was more predominant for the more modest group than for the less modest group.

Muslim ethnic identity. A Muslim ethnic identity was ranked as the most predominant identity by both groups. The results of the $t$-test revealed that this identity was more predominant for the more modest group than for the less modest group. According to Kaiser (1997, p. 53), one of the cultural perspective's assumptions is that "culture provides abstract pictures or representations of social life." Every culture provides guidelines for appropriate behavior and forms of dress, and "the character of Islam is modesty" (Boulanouar, 2006, p. 138). By wearing Islamic garments, a Muslim woman communicates her commitment to Islam (Shirazi, 2000). It is comprehensible that the more modest group would find their Muslim identity to be more predominant, as they are more in line with the dress requirements of the Islamic faith. In the research study, the majority of participants indicated that they associate themselves with other Muslim students (91.5\%) and that they take part in Muslim activities (73\%). This is an indication that participants strive to maintain their ethnic identity in the campus context.

Hybrid identity. A hybrid identity was ranked as the second most predominant identity by both groups. The majority of participants indicated that they have been Muslim all their lives and have also been living in South Africa their whole lives. They thus embrace their biculturalism and incorporate both identities in their dress practices. According to the cultural perspective, "People have the potential to transform their own realities by manipulating the objects in their cultural world" (Kaiser, 1997, p. 51). Cultural conventions can be broken by combining different dress forms to create new appearances. Different parts of one's identity can be prioritized depending upon the circumstances. A fusion of cultural influences is the end result (Dwyer, 2000). The majority of participants in the present study indicated that they mix Islamic and Western garments together, thereby confirming their association with both their ethnic and national identities. Participants are therefore biculturally oriented, as aspects of both cultures are combined and synthesized (Neuliep, 2009).

South African national identity. A South African national identity received the lowest scores from both groups. Even though the majority of participants (88\%) have lived in South Africa their whole lives, participants were not willing to rate their South African identity as being more important than their Muslim identity. Items such as "I am a South African, rather than a Muslim" and "I associate myself with students from other cultures, rather than from the Muslim culture" forced participants to choose between these two identities. They still placed more worth on their Muslim identity. A religious identity is a higher order identity and is more significant than the national affiliation 
of a believer (Sirin et al., 2008). Participants therefore viewed their religion as being more important than their nationality.

\section{Conclusion}

The study demonstrated how dress can be used to communicate differences that exist within a cultural group. All of the participants identified themselves as forming part of the Muslim community. These individuals followed a variety of dress practices, ranging from a complete Western appearance to a more Islamic one. Dress is a strong expressive tool and communicates the internal workings of the wearer (Kaiser, 1997). The fact that the group of participants who tended to wear more traditional Islamic garments was found to place more importance on religious values and a Muslim identity proves the symbolic nature of dress. The values and predominant identity of these individuals were reflected in their modest dress code as prescribed by Islam (Boulanouar, 2006). The group of participants who typically followed a Western-oriented dress code on campus was found to attribute more importance to social values. These individuals may have felt a greater need to fit into the campus context and therefore tried to look similar in appearance to other students. The prevalent values and identities of the participants were therefore directly translated into their external appearances. Dress is a meaningful way to understand the differences not only between cultures but also within cultural groups. Female Muslim students enrolled at a university in South Africa integrate aspects of South African thought into their Muslim selves to different degrees resulting in their variety of dress practices.

The results revealed that female Muslim students attending a university in South Africa incorporate more than one cultural identity in their dress practices. The findings correspond to findings about frame switching (Dwyer, 2000; Naylor, 1996). An individual may shift between frames in order to emphasize certain cultural identities in different parts of his or her life, depending on the context. At home, individuals may emphasize their Muslim identity, while on campus they may identify more with a South African or Western-oriented identity. Shifting between "cultural frames" may have an influence on individuals' dress practices since they behave in the most appropriate way as dictated by the social situation (Chattaraman, Rudd, \& Lennon, 2008; Upchurch, 2008). The majority of participants have been living in South Africa for their whole lives, which may have contributed to their adoption of some Western ways of life. Participants show evidence of communicating a hybrid identity as they integrate aspects of both their ethnic and national identities in their dress practices, albeit to different degrees (Schumann, 2011). Others may be able to understand the deeper meanings behind female Muslim students' clothing behavior as a result of these findings. This is a niche market with specific clothing needs and preferences. If retailers understand this group's consumption behavior, they may be able to attract the group's attention, create a loyal customer base, and thereby increase their market share (Patel, 2011). Retailers would be wise to take notice of this niche market and to widen their merchandise offering to appeal to Muslim women.

\section{Limitations of the Study}

This study was limited to a particular context - the campus of a university in South Africa - as well as limited to the enrolled female Muslim students. Future researchers could compare the values and identities of students from different campuses around South Africa as well as students from campuses overseas. Another limitation is that only students were used as the focus of the study. Future researchers could focus on other population groups. The fashion reference groups of participants were not explored. Muslim women may have different ideas about what constitutes fashionable dress and how to enhance their appearances. Researchers in future studies can investigate the fashions and reference groups that influence these individuals' dress practices. According to Kaiser 
(1997), when focusing on a cultural group, ethnographic studies (immersion of the researcher in the subculture) would yield the richest results. In the future, researchers could make use of qualitative methods in order to gain deeper insights into participants' beliefs and behaviors. This method of research would provide the full picture of the motives behind female Islamic dress practices.

\section{Declaration of Conflicting Interests}

The author(s) declared no potential conflicts of interest with respect to the research, authorship, and/or publication of this article.

\section{Funding}

The author(s) received no financial support for the research, authorship, and/or publication of this article.

\section{References}

Allport, G. W., Vernon, P. E., \& Lindzey, G. (1960). Study of values: A scale for measuring the dominant interests in personality. Boston, MA: Houghton Mifflin.

Arthur, L. B. (2000). Introduction. In L. B. Arthur (Ed.), Undressing religion: Commitment and conversion from a cross-cultural perspective (pp. 1-6). New York, NY: Berg.

Balasescu, A. (2003). Tehran chic: Islamic headscarves, fashion designers, and new geographies of modernity. Fashion Theory, 7, 39-56.

Bardi, A., \& Schwartz, S. H. (2010). Values and behavior: Strength and structure of relations. Personality Social Psychology Bulletin, 29, 1207-1219.

Benet-Martinez, V., \& Haritatos, J. (2005). Bicultural identity integration (BII): Components and psychosocial antecedents. Journal of Personality, 73, 1015-1049.

Bennett, R. J., Volet, S. E., \& Fozdar, F. E. (2013). "I'd say it's kind of unique in a way": The development of an intercultural student relationship. Journal of Studies in International Education, 17, 533-553.

Boonzaier, E., \& Sharp, J. (Eds). (1988). South African keywords: The uses and abuses of political concepts. Cape Town, South Africa: David Philip.

Bornman, E. (2005). National symbols and nation-building in the post-apartheid South Africa. International Journal of Intercultural Relations, 30, 383-399.

Boulanouar, A. W. (2006). The notion of modesty in Muslim women's clothing: An Islamic point of view. New Zealand Journal of Asian Studies, 8, 134-156.

Chattalas, M., \& Harper, H. (2007). Navigating a hybrid cultural identity: Hispanic teenagers' fashion consumption influences. Journal of Consumer Marketing, 24, 351-357.

Chattaraman, V., Rudd, N. A., \& Lennon, S. J. (2008). Identity salience and shifts in product preferences of Hispanic consumers: Cultural relevance of product attributes as a moderator. Journal of Business Research, $62,826-833$.

Creekmore, A. M. (1963). Clothing behaviors and their relation to general values and to the striving for basic needs (Unpublished doctoral dissertation). Pennsylvania State University, University Park, Pennsylvania.

Dastoor, B. R., Baumanis, L. O., \& Soomro, M. (2003). Acculturation and cultural values: Muslims in the U.S. and Pakistan. Academy of International Business Southeast USA (AIB-SE USA) 2003 Annual meeting, Clearwater, FL, 57-63.

Dunkel, T. M., Davidson, D., \& Qurashi, S. (2010). Body satisfaction and pressure to be thin in younger and older Muslim and non-Muslim women: The role of Western and non-Western dress preferences. Body Image, 7, 6-65.

Dwyer, C. (2000). Negotiating diasporic identities: Young British South Asian Muslim women. Women's Studies Forum, 23, 475-486.

Ferguson, J. G. (2002). Of mimicry and membership: Africans and the "new world society". Cultural Anthropology, 17, 551-569. 
Fernea, E. W., \& Fernea, R. A. (1995). Symbolising roles: Behind the veil. In M. E. Roach-Higgins, J. B. Eicher, \& K. K. P. Johnson (Eds.), Dress and identity (pp. 240-247). New York, NY: Fairchild.

Field, A., \& Miles, J. (2010). Discovering statistics using SAS. London, England: Sage.

Forney, J. D., \& Rabolt, N. J. (1997). Contemporary outer dress and clothing market source use of Middle Eastern women. Consumer Studies and Home Economics, 21, 55-73.

Frings, G. S. (2005). Fashion: From concept to consumer (8th ed.). Upper Saddle River, NJ: Pearson.

Glazer, S., \& Beehr, T. A. (2002). Similarities and differences in human values between nurses in four countries. International Journal of Cross Cultural Management, 2, 185-202.

Hassan, R. (2011). Identity construction in post-apartheid South Africa: The case of the Muslim Community (Doctoral dissertation). The University of Edinburgh, Edinburgh, Scotland.

Hassem, Z. (2008). An exploration of women's groups as a tool of empowerment for Muslim women in South Africa (Master's thesis). University of the Witwatersrand, Johannesburg, South Africa.

Henderson, A., \& McEwen, N. (2005). Do shared values underpin national identity? Examining the role of values in national identity in Canada and the United Kingdom. National Identities, 7, 173-191.

Hitlin, S. (2003). Values as the core of personal identity: Drawing links between two theories of self. Social Psychology Quarterly, 66, 118-137.

Hofmann-Towfigh, N. (2007). Do students' values change in different types of schools? Journal of Moral Education, 36, 453-473.

Hsu, H. (2003). National culture and clothing values: A cross-national study of Taiwan and United States consumers (Doctoral dissertation). Oregon State University, Corvallis, Oregon.

Jain, R., Singh, R., \& Rankawat, K. (2011). General values and clothing behavior of college-going students. Studies on Home and Community Science, 5, 13-20.

Kaiser, S. B. (1997). The social psychology of clothing: Symbolic appearances in context. (2nd ed.). New York, NY: Fairchild.

Kettani, H. (2010). 2010 World Muslim population. Proceedings of the 8th Hawaii International Conference on Arts and Humanities, Honolulu, Hawaii, 1-61. Retrieved from http://www.ohio.edu/orgs/muslimst/ downloads/World_Muslim_Population_2010.pdf

Khan, S. (2013). Religious co-existence: Tolerance and contestation amongst Hindu and Muslim faith groups of Indian origin in South Africa. Journal of Sociology and Social Anthropology, 4, 149-157.

Kilicbay, B., \& Binark, M. (2002). Consumer culture, Islam and the politics of lifestyle. European Journal of Communication, 17, 495-511.

Kim, E., \& Farrell-Beck, J. (2005). Fashion in context: Apparel styles worn by young women in the United States and South Korea in the 1970s. Clothing and Textiles Research Journal, 23, 180-202.

Kopp, H. (2002). Dress and diversity: Muslim women and Islamic dress in an immigrant/minority context. The Muslim World, 92, 59-77.

Markus, H. R., \& Kita yama, S. (1991). Culture and the self: Implications for cognition, emotion, and motivation. Psychological Review, 98, 224-253.

Momcilovic, O. G. (1998). Cultural origin: Effect on the relationship between selected human values and clothing values (Master's thesis). Texas Tech University, Lubbock, Texas.

Mooi, E., \& Sarstedt, M. (2011). A concise guide to market research: The process, data, and methods using IBM SPSS statistics. Retrieved from https://books.google.co.za/books?hl=en\&lr=\&id=vQ316cBxTM8C\&oi= fnd\&pg $=$ PR3\&ots $=$ HXXUTkZ0yg\&sig=tjVa2I6zB-LE4_f1IQF3PHA1514\#v=onepage\&q\&f $=$ false

Musangi, J. (2009). "Ayoba, Ama Kip Kip, Ayoba": The t-shirt cult in the forging of a black urban youth identity in Johannesburg. Scrutiny2, 14, 49-56.

Muthal, S. (2010). Subjective meanings attached to Muslim social identity in South Africa (Master's thesis). University of the Witwatersrand, Johannesburg, South Africa.

Naylor, L. L. (1996). Culture \& change: An introduction. London, England: Bergin \& Garvey.

Neuliep, J. W. (2009). Intercultural communication: A contextual approach (4th ed.). London, England: Sage. Patel, K. (2011). Fashion vs culture. Elle Magazine, South Africa, 16, 32-34. 
Peek, L. (2005). Becoming Muslim: The development of a religious identity. Sociology of Religion, 66, 215-242.

Pentecost, I. L. (1973). Influence values have on clothing selection by teenage girls (Master's thesis). University of Tennessee at Martin, Martin, Tennessee.

Phinney, J. S., Horenczyk, G., Liebkind, K., \& Vedder, P. (2001). Ethnic identity, immigration, and well-being: An interactional perspective. Journal of Social Issues, 57, 493-510.

Phinney, J. S., \& Ong, A. D. (2007). Conceptualization and measurement of ethnic identity: Current status and future directions. Journal of Counseling Psychology, 54, 271-281.

Rajagopalan, R., \& Heitmeyer, J. (2005). Ethnicity and consumer choice: A study of consumer levels of involvement in Indian ethnic apparel and contemporary American clothing. Journal of Fashion Marketing and Management, 9, 83-105.

Rokeach, M. (1973). The nature of human values. New York, NY: Free Press.

Rovine, V. L. (2009). Colonialism's clothing: Africa, France, and the deployment of fashion. Design Issues, $25,44-61$.

Sader, F. (2008). The identity of Muslim women in South Africa: Married couples' perspectives (Master's thesis). University of the Witwatersrand, Johannesburg, South Africa.

Schumann, S. (2011). Hybrid identity formation of migrants: A case study of ethnic Turks in Germany (Seminar paper). Munich, Germany: GRIN Verlag. Retrieved from http://www.grin.com/en/e-book/166974/hybrididentity-formation-of-migrants

Schwartz, S. H., \& Bardi, A. (2001). Value hierarchies across cultures. Journal of Cross-Cultural Psychology, $32,268-290$.

Shirazi, F. (2000). Islamic religion and women's dress code: The Islamic Republic of Iran. In L. B. Arthur (Ed.), Undressing religion: Commitment and conversion from a cross-cultural perspective (pp. 113-130). New York, NY: Berg.

Sirin, S. R., Bikmen, N., Mir, M., Finec, M., Zaal, M., \& Katsiaficas, D. (2008). Exploring dual identification among Muslim-American emerging adults: A mixed methods study. Journal of Adolescence, 31, 259-279.

Smith, M., De Klerk, H. M., \& Fletcher, L. (2011). Professional women's evaluation of the quality of career wear. Journal of Family Ecology and Consumer Sciences, 39, 33-46.

Storm, P. (1987). Functions of dress: Tool of culture and the individual. Englewood Cliffs, NJ: Prentice-Hall.

Tawfiq, W. A., \& Ogle, J. P. (2013). Constructing and presenting the self through private sphere dress: An interpretive analysis of the experiences of Saudi Arabian women. Clothing and Textiles Research Journal, 31, 275-290.

Upchurch, W. A. (2008). Relationship between level of acculturation and clothing preferences for Asian-Indian females (Master's thesis). Auburn University, Auburn, Alabama.

Vahed, G. (2000). Changing Islamic traditions and emerging identities in South Africa. Journal of Muslim Minority Affairs, 20, 43-69.

Van Der Merwe, W. L. (1996). Philosophy and the multi-cultural context of (post) apartheid South Africa. Ethical Perspectives, 3, 76-88.

Vincent, L. (2007). Steve Biko and Stoned Cherrie: Refashioning the body politic in democratic South Africa. African Sociological Review, 11, 80-93.

Wahl, S. C. (2014). Conversions to Islam: Personal narratives of Muslim women in Durban (Honor's thesis). Wesleyan University, Middletown, Connecticut. 


\section{Author Biographies}

Milde Albrecht completed her master's degree in consumer science at the Department of Consumer Science, University of Pretoria, South Africa.

Bertha Jacobs is a lecturer in the Department of Consumer Science, University of Pretoria. Her field of interest and research is fashion retailing, clothing merchandising, social psychology of clothing, and professional development of students for industry.

Arda Retief is a lecturer in the Department of Consumer Science, University of Pretoria. Her research interests include textiles, new development in textiles, and consumer behavior in the clothing field.

Karien Adamski completed her PhD in mathematical statistics at the Department of Statistics, University of Pretoria, South Africa. 